\title{
J.M. Bocheński's method of philosophical analysis and contemporary applied ontology
}

\author{
Marek Lechniak
}

Published online: 27 August 2013

(C) The Author(s) 2013. This article is published with open access at Springerlink.com

\begin{abstract}
The aim of this article is to reconstruct Bocheński's method of philosophical analysis as well as to clarify the purpose of that method and its basic elements. In the second part of the paper I will compare Bocheński's method with the methods of modern applied ontology.
\end{abstract}

Keywords Philosophical analysis · Logic $\cdot$ Authority $\cdot$ Formal ontology

\section{Introduction}

J.M. Bocheński conducted benchmark analyses of a number of concepts belonging to different domains, such as authority, religion, the free society, the industrial enterprise. In these analyses Bocheński applied a method he developed himself, in which logical tools were of vital importance. In the article I will reconstruct the purpose of that method and its basic elements. In the second part of the paper I will compare Bocheński's method with the methods of modern applied ontology.

\section{Bocheński: between logic and ontology}

Bocheński's philosophical activity can be briefly described as philosophical analysis (or its result as analytic philosophy). In his programmatic statement, presented in "Über die analytische Philosophie" (Bocheński 1986a), "Logic and Ontology" (Bocheński 1974c) and in numerous observations contained usually in the introductions to his analytic works, Bocheński insisted that he cultivated a kind of basic research, which seeks to understand what other disciplines presuppose. It is analytic philosophy, in

M. Lechniak ( $\square)$

Faculty of Philosophy, John Paul II Catholic University of Lublin, Lublin, Poland e-mail: lechmar@kul.lublin.pl 
which one conducts "a simple, sober, logical analysis of language. [...] Therefore, analytic philosophy is primarily an analysis of language, words are indeed not taken into account here in the abstract sense, i.e. in isolation from the living language. On the contrary, different ways of using words are explored to determine their meaning better. That is to say, however, that these meanings are determined by continuous comparison with the reality reflected in language" (Bocheński 1974a, p. 12).

The program of practicing analytic philosophy can be summarized in the following schema: a philosopher, using the tools of logic (the consequence of the use of logic is simplicity and sobriety), performs linguistic analysis based on the examination of words in ordinary language in order to grasp their meaning; such an approach assumes, of course, the correspondence of language and reality (which is reflected in language).

Philosophical analysis is of a logical character. Therefore, philosophy adopts, according to Bocheński, the form of applied logic. "This may seem strange to a reader who regards logic as a reasoning technique. In fact, logic is a completely different thing; it is above all a theory of the most general, simplest connections between all things, and thus a great tool not as much for reasoning as for analysis" (Bocheński 1974a, 12). It is worth mentioning that Bocheński pointed to three important functions of logic in philosophy, namely: the educational function (paidagogos), the instrumental function (organon), and the informational function (meros), by means of which some logical statements lead to the solution of philosophical problems. However, the most important function of logic is its use as a tool for the analysis of concepts (Russell's theory of descriptions, Tarski's theory of truth or his own conceptual analyses serving as examples) (Bocheński 1988a, b).

Bocheński's analytic papers are in line with the program of Polish analytic philosophy initiated by K. Twardowski and J. Łukasiewicz, whose followers include, among others, T. Kotarbiński, K. Ajdukiewicz, and T. Czeżowski. In the paper "Analiza i konstrukcja pojęcia przyczyny" (Łukasiewicz 1961, 9-65) Łukasiewicz distinguished two operations aimed at the determination of the concept: analysis and construction. "To provide a logical analysis of a concept, or an abstract object is to find all its features and explore the relationships that occur between them, with a particular emphasis on the necessary relationships, that is on the designation of both defining and consecutive characteristics" (Łukasiewicz 1961, 12). But, as he noted, it is not possible to provide all the features of a given concept, because besides absolute features, it has an unlimited number of relative features. An additional difficulty stems from the fact that in everyday language we use the word corresponding to the concept in various situations usually knowing which thing we have in mind. Therefore, to obtain the definition of a concept the analysis must be supplemented with a structural element. "To create, or construct, an abstract object means to find certain features, to consider which of them can be connected with each other, and which should be removed, and thereby to obtain a complete collection of features connected by relationships that would constitute precisely the object of research" (Łukasiewicz 1961, p. 13). ${ }^{1}$ Thus, according to Łukasiewicz, the meaning of a word in ordinary

\footnotetext{
${ }^{1}$ S. Kamiński distinguishes the following conceptions of philosophical analysis (derived from "classical analysts, not school related authors"): (1) treating the analysis as a definitional-explanatory operation; (2)
} 
language is to be reconstructed, and the determination of the meaning of a name should resemble efforts towards providing a regulatory definition.

Bocheński, as we will show by studying examples of his analysis of concepts, applied Łukasiewicz's program. Philosophical analysis aims at defining clearly the concepts used in other disciplines. Modern development helps philosophers recognize that they can do a favor for other disciplines, that not only they alone but others can utilize their results. In the Middle Ages there was much discussion about the role of philosophy as ancilla theologiae. Many modern philosophers found that offensive-How could their dignified wisdom be a servant? Their indignation might not have been as radical had they heard the term 'auxiliary' instead of 'servant' discipline- since such is the meaning of the medieval 'ancilla'. None of the mathematicians feels offended by the fact that an astronomer uses his science as an auxiliary discipline. Why would philosophers react differently? (Bocheński 1993, 46).

Philosophy is to be a propaedeutic to the domains of specific sciences (Aristotle attributed this role to the Organon) Bochenski listed four distinctive features of analytic philosophy-focusing on small tasks (rather than creating syntheses); clear expression; relying on logical tools; objectivity_allow philosophical propaedeutic to be seen as neutral in content. That neutrality is due to the fact that the analysis is carried out solely in order to determine the basic properties of the analyzed concept (Bocheński 1974a, p. 13), and philosophical analysis is based on the most general categories of ontology (and ontologically understood logic) (Bocheński 1974c, 285-288).

In the next section we will present the way to implement Bocheński's method. The key stages of the analysis of a concept will be extracted on the basis of the analysis of the concept of authority. Since the object of this paper is concept analysis, we omit other papers by Bocheński on formalization, such as those on the formal analysis of the arguments for the existence of God. ${ }^{2}$

\footnotetext{
Footnote 1 continued

limiting the analysis to a (syntactic) reduction of formulas, and (3) identifying the analysis with a linguistic and pragmatic study of the ways to apply formulas. Apparently, reductive analysis is closest to Łukasiewicz's and Bocheński's programs; according to Kamiński, "assuming isomorphy between atomic sentences and the corresponding elementary facts, the analysis is carried out bringing complex and descriptive ontological statements to the language of logic, which allows for a deeper and clearer insight into the structure of the world"; cf. Kamiński (1993, 135-136), J. Woleński indicates the following methods of analytic philosophy: the method of logical construction, Carnap's method of explication, Ajdukiewicz's method of paraphrase, the method of presupposition and argumentation from reference cases; Bocheński's approach would probably be closest to the method of logical constructions or to that of paraphrases, cf Woleński (1989).

${ }^{2}$ I focus mainly on the book Was ist Autorität (Bocheński 1974a) and related articles, with references to other works by Bocheński.
} 


\section{Conceptual analysis applied to the concept of authority}

Bocheński uses the above mentioned program to the fullest in the analysis of the concept of authority (Bocheński, "Was is Autorität?," "An Analysis of Authority," "On authority"). The paper "Was is Autorität?" is written in ordinary language, but it was preceded by an analysis carried out in formal language in the article "An Analysis of Authority." ${ }^{3}$ In the latter work Bocheński notes that "what is offered here is an analysis which is, in most cases, purely logical, more exactly pragmatic, but conducted with formal logical tools. However, a few empirical assumptions are made. Those assumptions are valid only where human authority is concerned, consequently, the portions of our study based on them deal with that authority alone. On the other hand, whatever is not based on those assumptions applies to all possible entities, i.e. to God also. A theory of every possible authority is constructed." (Bocheński 1974b, 56). The analysis of 'authority' is based, at least partly, on empirical assumptions (meaning: 'extra-logical'), because it is related to a concept from outside logic, namely a concept from ethics or epistemology; it has an ontological character-it applies to every possible authority, and is carried out with the use of logical tools. Those are from first order logic; in his work Bocheński rather does not refer to logical means from outside Principia Mathematica.

The primary objective of the analysis of a concept is to formulate a definition. According to Bocheński, it is to be a classical definition, that is, through specifying genus proximum and differentia specifica. The adoption of the classical definition as the objective of the analysis results in view that the aim of analysis a logical division of the concept's extension.

In Bocheński's analysis of the concept of authority we can distinguish the following stages:

1. Reference to the meaning of the analyzed expression in a natural language (everyday language or professional jargon). The starting point is an introductory analysis related to the everyday use of the word "authority." Bocheński here goes back to the colloquial phrases containing the expression "authority," pointing to the ambiguity of the word: it can be understood in the sense of something that is an attribute of someone (feature) or something that has the nature of a relationship (one is an authority for someone). ${ }^{4}$

2. Organizing intuitions associated with the use of an appropriate natural language concept. This requires differentiating the various meanings of the word by distinguishing different contexts of its use.

\footnotetext{
${ }^{3}$ (Bocheński 1974b). In that article Bocheński indicates that the analysis is an extension of some of the statements contained in Logic of Religion.

${ }^{4}$ Similar remarks can be found for example in "Analyse der industriellen Unternehmung," (Vortrag gehalten am 18. März 1985, Bank Hofmann AG, 1985; in Bocheński 1988b, 119-150), where the author draws attention to the fact that the concept of a company is such that "Es sieht so aus, als ob eine Definition der Unternehmung im allgemeinen, das heißt eine eindeutige Bestimmung des Sinnes des Wortes "Unternehmung", nicht möglich wäre" (120). Due to the lack of the possibility to refer to colloquial language in which intuitions concerning understanding an enterprise are unclear, the author examines various economic conceptions of an enterprise.
} 
3. Finding the closest kind, that is, the specific locus ontologicus of the concept, or establishing the category to which the examined concept belongs. In the case of the concept of authority the category of relationship rather than the category of property is the genus. ${ }^{5}$ Consequently, the analysis of the genus 'relation' is reduced to determining how many components it has and analyzing the components of that relation (in the case of property-the analysis of its subject) ${ }^{6}$ including the determination of the ontological category of the relation's components. For the relation of authority the components are: the subject of authority (person with authority), the object of authority (the person for whom one is an authority) and an domain of authority (i.e. a set of statements or directives concerning authority).

4. Determining formal properties of a relation that will distinguish the relation of being an authority from other ternary relations, and will thus somehow serve as the differentiae specificae. Both in order to define genus as a relation, and, above all, to determine the terms of property relations, a formal theory of relations is particularly helpful.

5. Introducing a division within the analyzed concept. Logical division of the extension of a concept (name) must be preceded by a search for the principle of the division. Thus, after determining the properties of the divided concept its more extensive determination is acquired by means of a logical division: the search for the principle of the division is based on the discovery of a property that assumes at least two modifications determining individual components of the division. Bocheński divides 'authority' according to the type of objects belonging to the realm of authority. For the concept of authority these are propositions (statements in a logical sense) and directives (norms) ordering such and such an action. Thus, if statements make up the realm, we have epistemic authority (concerning the truth of the propositions), and if directives make up the realm, in that case we have deontic authority (concerning the recommended actions of the object of authority).

6. Analyzing individual components of the division. The analysis begins with attempts to define the essence of each of the components of the division and presenting the properties of the defined concepts. For example, for the concept of deontic authority it is important to distinguish between two types of authority-sanctions and solidarity. That distinction is based on the principle that the purpose of the object of authority may be consistent with the objective

\footnotetext{
5 The concept of authority shares the fate of many 'shortcut concepts' in which a relational phrase gets "wound down" to a property phrase (analogous to saying that Joanna is a mother; but the phrase, "is a mother" is relational, because Joanna is the mother of someone. In such cases, one can speak secondarily about the feature "is a mother": $x$ is a mother if there exists $y$ such that $x$ is a woman and $x$ is in the relation of being a mother towards $y$ ).

6 Sometimes the genus of a given kind is of a complex character, beyond Aristotle's list of categories, as, for example, in "Analyse der industriellen Unternehmung" where Bocheński points out that the classical categories are not suitable to identify adequately the genus of the genre 'enterprise'. "Stößt man in der Suche nach der Gattung auf solche Schwierigkeiten, dann soll man-einem alten methodologischen Ratschlag folgend-“die Leiter der Abstraktion hochklettern", das heißt, zu immer abstrakteren Begriffen aufsteigen, bis zu den allgemeinsten überhaupt, den Kategorien. (...) Kategorien gibt es nämlich im wesentlichen drei: Ding, Eigenschaft und Beziehung” (Bocheński 1988b, 122).
} 
of the subject of authority (authority of solidarity) or inconsistent (authority of sanctions).

Those points define the various stages of the analysis of the concept of authority. Sometimes the process of defining is different. For example, in "The concept of the free society" Bocheński, while defining the concept of individual freedom, refers to the pre-defined notion of authority; then, following a combinatorial analysis of various possible types of society distinguished in terms of its relation to the freedom of an individual, he seeks to provide an adequate definition of a free society by setting down, first, a necessary, then a sufficient condition for a free society. ${ }^{7}$ Of course, the above steps are not always present and not always in exactly the same order.

Now it is worth looking at the means of formal logic to which Bocheński had recourse in his analysis.

\section{Means of formal logic used in philosophical analysis}

Symbolization and the language of first order predicate calculus with identity

The procedure of symbolization is crucial for Bocheński's analysis, he clearly distinguishes symbolization, that is, writing down relevant extra-logical theorems in symbolic language, from formalization: "Regarding logical symbolism, it must be stressed that the use of artificial symbols is not to be understood as a formalization. For formalization is a procedure by which one abstracts from the meaning of terms and operates on the shapes of the (material) symbols alone-which will not be done here. The symbolism is rather used as a useful shorthand, without which it would be difficult to obtain statements of the desired precision" (Bocheński 1986b, 207). Certainly, when deciding on formalized equivalents of extra-logical expressions you need to choose a formal language in which the symbolization will be executed. The choice of language determines which theses can be expressed in it and with which degree of precision. The formal language used by Bocheński is the language of first order predicate calculus with identity. Many relationships between the properties of the analyzed concepts are derived from the laws of the predicate logic. Bocheński uses neither non-classical logics in his language analyses, nor, for example, Leśniewski's systems. According to Bocheński, the means of classical logic are sufficient for a formal account of philosophical theses under analysis. ${ }^{8}$

\footnotetext{
7 See Bocheński (1986b). When determining the concept of the free society Bocheński follows the following steps: specifying the necessary condition for the free society, strengthening the necessary condition by adding a new condition, further restricting the analysis to specific cases and exceptions.

8 This does not rule out the fact that he knew and respected some non-classical logics, for example he mentions Łukasiewicz, Heyting, and Leśniewski as authors who articulated the carefully refined ontological intuitions of their respective logics; cf. Bocheński (1974c).
} 
Theory of relations

Bocheński devoted a lot of attention to the logical theory of relations, because many of the concepts he studied are relations. The article "An analysis of authority" is a contribution to the theory of ternary relations. Bocheński shows there that for ternary relations the distinction: domain-range loses its meaning: one should talk instead about three domains, and that ternary relations are reducible to binary relations. ${ }^{9} \mathrm{He}$ also defines some properties of ternary relations indicating that a given property of a relation (e.g., its symmetry) can hold in a number of ways. ${ }^{10}$ Multiple components of the analyzed relations (for example, the concept of authority or a free society) presuppose the method of formal analysis, named by Bocheński "generalization."

\section{Generalization}

In Polish methodology generalization used to be referred to as an operation on the intension of a name, aiming at finding the name of a range broader then the given name. ${ }^{11}$ Bocheński uses the term in a slightly different sense, generalization being quantification over variables that are the arguments of a predicate denoting a relation. "By listing them, we obtain a logical frame for a classification of different societies in regard to freedom. Such a classification can only be made with the use of contemporary mathematical (Fregean) formal logic, which alone (contrary to the so-called 'conventional' logic) offers a theory of multiple quantification. Such quantification is needed here, because we have to operate on a matrix with two variables." (Bocheński 1986b, 208). It is therefore a formal generalization, involving finding for each relation all of its generalizations, understood as identifying all possible claims of a general nature (i.e. both with a general and specific quantification) concerning the subject of the analyzed relation holding between certain classes of objects (its components). The aim of such a procedure is a kind of combinatorial analysis leading to a review of all the possible types of concepts corresponding to a given relation. Obviously, some generalizations are reducible to others because of the laws for quantifiers. ${ }^{12}$ Sometimes, for example in

\footnotetext{
9 These are: the relation of a subject to the object of authority [that is a set of ordered pairs $\mathrm{x}, \mathrm{y}$, such that there exists a domain $\gamma$ such that $\mathrm{A}(\mathrm{x}, \mathrm{y}, \gamma)]$, a subject to the domain and the object to the domain and their converses.

10 There can exist twelve such notions of symmetry for a ternary relation. For the relation of authority, however, there are fewer-only two, because the third component, the domain, belongs to a different logical type than the first two, and there is no point rearranging the order of the individuum-a set, see Bocheński (1974b), 61.

11 According to Czeżowski, generalization is a logical addition, e.g. for the name "square" we can find a superior type, "a square or inequilateral rectangular parallelogram." "The transformation carried out on the term 'square' replaces the component 'equilateral' in its connotation with a logical sum, 'equilateral or inequilateral"”; cf. Czeżowski (2009), 96.

12 That is, the laws of changing the order of quantifiers. Thus, for example, the number 48 generalizations of three variables is, by the aforementioned laws, limited to 26 . These in turn are mutually connected by entailment relations under the laws of subordination, that is $\forall x A(x) \rightarrow \exists x A(x)$ or the law of interchanging existential quantifiers with general quantifiers, i.e. $\exists x \forall y P(x, y) \rightarrow \forall y \exists x P(x, y)$.
} 
the article "The concept of the free society," such an analysis is beneficial, showing mutual logical relations between different types of freedom in society, because "each of these generalizations describes the structure of one of the a priori possible simple types of societies in regard to freedom" (Bocheński 1986b, p 209). Similarly, for the concept of authority we can examine the relationships among various positions, for example with regard to the issue of epistemic authority, thanks to the analysis of the relations among "generalizations."

\section{Logical theorems and extralogical theorems}

The analyses of concepts presented by Bocheński are, as already indicated, of a philosophical nature and therefore, generally speaking, extralogical. Bocheński is trying to show the way of justifying the proposed statements (as, for example, in "An analysis of authority"), but often, especially in the papers free of symbolic notation (e.g. "What is authority?"), in the proofs Bocheński provided of his statements it is difficult to distinguish the purely logical from the extralogical means, such as empirical observations or intuition. It should also be noted that the introduced definitions usually take the form of statements of the system rather than rules of substitution. Bocheński treats them as real definitions and tries to justify them intuitively. Many other statements are logical consequences of the definitions, and in Bocheński's papers one can find theses, which he treats as axioms, for example, the existence axiom for the theory of authority: "Everyone is an authority in at least one field for everyone else" (i. e., in symbolic notation): ${ }^{13}$

$$
\forall x \exists \gamma \forall y(x \neq y \rightarrow A(x, y, \gamma)) .
$$

\section{Philosophical analysis and formal applied ontology}

As shown above, Bocheński treated practicing philosophy as a logical analysis of concepts (in a broad sense). Its objective is the definition of concepts vital for specific non-philosophical disciplines to ensure their accuracy and terminological precision. The analysis is thus understood as prescientific, a kind of propaedeutic to science. How does analytic philosophy in Bocheński's understanding relate to contemporary formal ontology?

Contemporary formal ontology is characterized as "the result of combining the intuitive, informal method of classical ontology with the formal, mathematical method of modern symbolic logic. Formal ontology, the result of combining these two methods, is the systematic, formal, axiomatic development of the logic of all forms and modes of being" (Cocchiarella 1991, 640). Bocheński applied both the intuitive method and the methods of formal logic. So he fulfilled the first part of Cocchiarella's characterization. However, the result of the research in formal

\footnotetext{
13 Bocheński notes here that "all [theorems] are based on experience and can not be obtained by linguistic analysis alone. However, the acceptance of only one directly based on experience is necessary since a large number of other theorems is implied by it in the framework of the basic ones" (Bocheński 1974b, 66).
} 
ontology should be, according to Cocchiarella, a logical axiomatic formal system. Bocheński's analysis did not go so far, stopping at the pre-formalized stage. Bocheński did not provide an axiomatic system and applied his analysis to fairly narrowly defined problems. According to him, the analysis was not meant to provide a comprehensive system of all the forms and ways of being, but merely lead to precision in the use of certain concepts applied in other fields of knowledge. Was thus Bocheński the forerunner of applied ontology?

There are today many applied ontologies (Garbacz and Trypuz 2012). Applied ontology is to be a "specification of conceptualization," which means that as a conceptualization it is a simplified and abstract view of the world, expressed in a language (specification) by logical means. ${ }^{14}$ Its purpose is thus a formal characterization of the conceptual apparatus of a specific subject area (while the attributive "engineering" indicates that the first goal of this ontology is practical utility and not full adequacy or simplicity). Some of these ontologies are complex systems containing many conceptual categories and the relations binding them on the basis of which specific programming tools can be constructed. In the light of that fact someone might deem Bocheński's achievements unimportant. But one should keep in mind that Bocheński's works come from the 70 s and 80 s of the last century, and applied ontologies started developing much later. Applied ontologies were created for technical purposes and entire research teams have been working on them.

Unfortunately, the lack of technical applications for the developed concepts is the reason why Bocheński's analyses should be treated as prolegomena to the appropriate applied ontologies. ${ }^{15}$ The demand for "working" ontologies, that is, those which provide foundations for representing practical knowledge, obliges systems developed for practical reasons to face a number of particular problems. Therefore, some of the results presented by Bocheński may seem to be too "thick" since they do not take into account the achievements of particular scientific disciplines. For example, the results of the analysis of authority may be subject to allegations by sociologists and social psychologists who, should they try to apply this theory, probably would notice the many problems left unrefined or Bochenski's disregard for the requirements of applicability.

When it comes to comparing Bocheński's achievements with formal ontologies in terms of the attitude towards logical tools, it can be said that applied ontologies often take the form of elaborate definitional-axiomatic systems. A number of noncontradictory axioms are used which are often dependent on each other; because mutual independence is not an important feature of the system, formal logicians have often criticized such systems as inelegant. But their purpose is to characterize reasonably accurately the concepts of a domain. Although the language of these systems is essentially a first order language, it happens to go beyond that language by using, for example, mereology. In Bocheński's work, as we have indicated, we have more of an intuitive analysis supported by the language of first order logic, it is

\footnotetext{
14 As an example of an applied ontology we can cite the ontology of beliefs contained in Garbacz et al. (2009).

15 Although Bocheński's theory of authority goes well beyond the content expressed symbolically and can be the basis for a large broad ontology of authority.
} 
an analysis at a pre-formalized stage - the language of logic supports the precision of the definitional actions and enables the derivation of basic logical relations among concepts. The result of the analysis does not take the form of an axiomatic system but, at most, the form of a set of statements and definitions related by the content and form.

Open Access This article is distributed under the terms of the Creative Commons Attribution License which permits any use, distribution, and reproduction in any medium, provided the original author(s) and the source are credited.

\section{References}

Bocheński, J. M. (1974a). Was is Autorität, Einführung in die Logik der Autorität, Freiburg in Breisgau: Herder.

Bocheński, J. M. (1974b). An analysis of authority. In F. J. Adelmann (Ed.), Authority (pp. 56-85). The Hague: M. Nijhoff.

Bocheński, J. M. (1974c). Logic and ontology. Philosophy East and West, 24(3), 275-294.

Bocheński, J. M (1986a). Über die Analytische Philosophie. Eröffnungsvortrag. In: Die Aufgaben der Philosophie in den Gegenwart. Akten des 10. Internationalen Wittgenstein Symposiums. 18-25 VIII 1985 Kirchberg am Wechsel. Wien pp. 22-29, Polish translation (1987/1993), O filozofii analitycznej. In: J.M. Bochenski. Logika i filozofia Warszawa: PWN pp. 35-49).

Bocheński, J. M. (1986b). The concept of the free society. The Monist, 69(2), 207-215.

Bocheński, J. M. (1988a). Co logika dała filozofii? [What is logic for philosophy?] Studia filozoficzne' 6-7, 7-14.

Bocheński, J. M. (1988b). Analyse der industriellen Unternehmung. In: J. M. Bocheński. Autorität, Freiheit, Glaube. Soziaphilosophische Studien, (pp. 119-150). München/Wien: Philosophia Verlag.

Bocheński, J. M. (1993). Logika i filozofia. Warszawa: PWN.

Cocchiarella, N. B. (1991). Formal ontology. In H. Burkhard \& B. Smith (Eds.), Handbook of metaphysics and ontology (Vol. 2, pp. 640-647). Münich: Philosophia.

Czeżowski, T. (2009). Generalizacja, abstrakcja, formalizacja In: T. Czeżowski. Filozofia na rozdrożu (Philosophy at the Crossroads), 2nd edition. Toruń, pp. 96-105.

Garbacz, P., Kulicki, P., Lechniak, M., \& Trypuz, R. (2009). Do you still want to vote for your favorite politician? Ask Ontobella!. In FOMI 2009: 4TH Workshop on formal ontologies meets industry. IOS Press, pp. 102-113.

Garbacz, P., \& Trypuz, R. (2012). Ontologie poza ontologią. Studium metateoretyczne u podstaw informatyki [Ontologies beyond ontology. A metatheoretic study of the foundations of informatics]. Lublin. Wydawnictwo KUL

Kamiński, S. (1993). Argumentacja filozoficzna w ujęciu analityków [Philosophical arguments according to analytic philosophers]. In S.Kaminski: Filozofia i metoda, edited by J. Herbut. Lublin: TN KUL, pp. 133-149.

Łukasiewicz, J. (1906/1961). Analiza i konstrukcja pojęcia przyczyny [The analysis and construction of the concept of cause]. Przeglad Filozoficzny. 9 (1906), pp. 105-179. Z zagadnien logiki i filozofii. Warszawa: PWN (1961), pp. 9-65.

Woleński, J.(1989). Kierunki i metody filozofii analitycznej w [Currents and methods of analytic philosophy]. In J. Perzanowski (Ed.) Jak filozofować?. Warszawa: PWN, pp. 30-77. 